\title{
Time, Intellect and Human Ego
}

\section{Berov G. Lyubomir}

Engineer, Independent Innovative Ideas Researcher, Smolyan 4700, Bulgaria. my_kaly1@mbox.contact.bg

Abstract: This is, I think, the connection between the intellect and the time - the intellect is capable and most likely defines the sequence of events.

Keywords: Time, Intellect, Human ego, Sequence of events, Supreme Intelligence,

Dear reader, with this article I will try to show the connection between time and intellect as I understand it. And by the way, the impact of the human ego in understanding this connection

Now you will see that not only you do not understand much of time, space and the like. I am one of them. But that will not prevent us from discussing such topics. This is so human, isn't it? And I think the accumulated ballast of knowledge is sometimes an insurmountable obstacle to perceiving qualitatively new ideas, so the lack of knowledge can help us understand the new idea I'm considering below.

So the term "time"? Among the most prominent people of science there are two views regarding time. One is that it is part of the fundamental structure of the universe, a real dimension in which events happen in succession. The other is that time does not refer to any real dimension, but is an intellectual concept that allows people to track, compare, and arrange events.

Great Einstein said, "Time has no independent existence except the order of events by which we measure it. Time is the sequence of events - that's my conclusion. "Later in the General Relativity theory, it shows how time and space are interconnected, and in the vicinity of massive bodies the flow of time slows down because the mass of the bodies distorts time-space and the gravity is precisely this distortion.

But let's not complicate things. For me, time is a sequence of events, and it can be one for an observer from a particular inertial system, and quite different for an observer from another inertial system that moves toward the first. So, in order to have "time", there must be an observer, or more precisely, an intelligent person who realizes the sequence of events he sees. And the "time" thus explained is subjective. In this situation there is something else, very important - if the observer can choose the speed of movement of the inertial system it can influence the time. Of course, to notice this effect, the difference in the speeds of motion must be close to the speed of light. This is, I think, the connection between the intellect and the time - the intellect may and probably most likely define the sequence of events.

But, dear reader, let's not be fooled - it is not about the human intellect. We humans have reached a level that we can only observe, but not change the course of time on galactic scale. The reason I think is that we are too insignificant, too poor in energy. However, nature has given us an immeasurable "ego," and we very rarely realize this. And the thesis, "Man is the greatest creation of nature," which is the basis of our "ego" is infinitely wrong. It has brought, bears and will continue to bear lots of troubles to mankind. It makes it difficult for science to start on new ways in exploring radically new ideas.

I think this is exactly the case with the following idea: "Supreme Intelligence determines the sequence of events and the events in the universe itself." What is this Supreme Intelligence? You can call it God, but I put other content in it, different from the religious one. Here is my hypothesis: All the particles in the universe, apart 
from the qualities known to science, carry a unit of intellect. What amount of intellect is this? For now, it's not clear, but that's not important. On the other hand, you dear reader, I, the unadulterated writer, and all the other sensible and unreasonable living creatures, and the non-living, too, since we are made of these particles, are also intelligent. Of course, the intellect of every material being, whether it be alive or not, is different and manifests itself in a familiar way, and most often in a completely unknown way. Taken as such, things mean that Supreme Intelligence is the basic substance of our world, and matter has added to it, and it is no problem for Supreme Intelligence to create and organize what events he decides to be necessary to achieve its goals. What are the goals? Only he knows!

In support of this hypothesis I will point out very few but extremely important facts:

In order to create the conditions so we humans can exist, science has found by observing that there are many fundamental numbers, such as the electric charge of the electron, the relationship between the masses of the proton and the electron, and others that are absolutely necessary to be exactly what they are. For example, if the electric charge of the electron was a bit different, the stars would either not be able to use hydrogen and helium as fuel, or they would explode - and this is a fatal situation for everything living on the planet Earth. This is the role of the Supreme Intellect.

However, our intellect is sufficient to draw conclusions from observations and sometimes find explanations of some natural phenomena. Of course, it is often necessary to change scientific theories and philosophical concepts, to create new ones, but such is any development.

And how does our "ego" interfere with this development? Here is an example: The creation of the atomic bomb. It was a hopeless experience on the path of increasing the power of man. And the result is the progression of the regular war in the so-called cold war, which continues now and takes huge resources of all kinds. And the end of this misery is not to be seen. Another example - In US is signed a law defining NASA's main goal for the coming decades. These are piloted missions in the distant cosmos, with the focus being the planet Mars. NASA has to work for "a piloted mission to Mars in the thirties of this century. Reaching the Red Planet, which is 225 million kilometers from the Earth, and staying there requires a technological feat and a huge budget. "What is the goal? The goal is to conquer the cosmos, which is in any case controlled by the Supreme Intelligence. I.e. our ego requires our playing the role of our creator. And this is wrong, engages a large part of the scientific elite and requires a huge budget. I believe that it is not necessary to give similar examples of decisions made in Russia, China and other nations. And what is right? In my opinion, it is more appropriate that this huge budget be devoted to establishing real connection with intelligent creatures from the next levels close to us. Perhaps then we will become even more powerful, but not as the only intelligent beings in the universe, but as intelligent beings who know their place among other intelligent beings.

What do you think dear reader, is there anything real in my dream?

Citation: Berov G. Lyubomir, "Time, Intellect and Human Ego", American Research Journal of Physics, vol 5, no. 1, pp. 1-2.

Copyright (C) 2019 Berov G. Lyubomir, This is an open access article distributed under the Creative Commons Attribution License, which permits unrestricted use, distribution, and reproduction in any medium, provided the original work is properly cited. 